\title{
Optimal PI Kontrolör Tasarımı için Üçgenler Ağında Lineer Enterpolasyon Yöntemiyle Kararlılık Sınır Yüzeyinin Oluşturulması
}

\author{
Gürkan KAVURAN* \\ Malatya Turgut Özal Üniversitesi, Mühendislik ve Doğa Bilimleri Fakültesi, Elektrik-Elektronik Mühendisliği, \\ Malatya \\ (ORCID: 0000-0003-2651-5005)
}

\begin{abstract}
$\ddot{O} \mathbf{z}$
Bu çalışmada, PI parametrelerinin grafiksel olarak hesaplanması için geliştirilen kararlılık sınır eğrisi kullanılarak, yeni bir yaklaşım önerilmiştir. Geleneksel kararlılık sınır eğrisi, kapalı çevrim sistemin karakteristik polinomu kullanılarak, kontrolör parametrelerinin belirli bir frekans aralığında birbirine göre çizimiyle elde edilir. Kararlılık sınır eğrisi altında kalan bölgedeki herhangi $k_{p}$ ve $k_{i}$ değerinin sistemi kararlı yaptığı bilinmektedir. Ancak hatanın değişimine göre hangi parametrelerin optimal sonuç verdiği kesin değildir. KSE altında kalan her nokta belirli bir frekans aralığında dağınık veri enterpolasyon yöntemine göre belirlenerek, 3 boyutlu kararlılık sınır yüzeyi (KSY) oluşturulmuştur. Çoğunlukla sistem kararlılığını garanti eden bu noktalar kullanılarak, kararlı $k_{p}$ ve $k_{i}$ parametre havuzu oluşturulmuştur. Havuzdaki her bir $k_{p}$ ve $k_{i}$ değerinin birbiriyle olan kombinasyonu kullanılarak, ITAE kriterine göre referans girdi ile sistem çıkışı arasındaki farkı minimize eden optimal PI parametreleri elde edilmiştir. Böylece hem kararlılık hem de optimallik sağlanmıştır. Benzetim çalışmalarının yanı sıra, çift rotorlu model helikopter sistemi üzerinde önerilen yöntemin geçerliliği test edilmiştir.
\end{abstract}

Anahtar kelimeler: PI kontrolör, kararlılık sınır eğrisi, kararlılık sınır yüzeyi, dağınık veri enterpolasyonu, çift rotorlu model helikopter.

\section{Formation of Stability Boundary Surface by Linear Interpolation Method in Triangles Network for Optimal PI Controller Design}

\begin{abstract}
In this study, a new approach has been proposed by using the stability boundary locus which is developed for the calculation of PI parameters by graphically. The conventional stability boundary locus is obtained by drawing the controller parameters relative to each other in a specific frequency range using the characteristic polynomial of the closed-loop system. It is known that any $k_{p}$ and $k_{i}$ values in the region under the stability curve makes the system stable. However, it is not clear which parameters give optimal results according to the change of error. Each point under the SBL was determined according to the scattered data interpolation method within a certain frequency range and the 3D stability boundary surface (SBS) was formed. The stable $k_{p}$ and $k_{i}$ parameters pool which mostly guarantee the system stability has been established by using these points. The optimal PI parameters were obtained which minimized the difference between the reference input and the system output according to ITAE criteria by using the combination of each $k_{p}$ and $k_{i}$ values in the pool. Thus, both stability and optimality were achieved. The validity of the proposed method was tested on a twin rotor helicopter system in addition to the simulation studies.
\end{abstract}

Keywords: PI controller, stability boundary locus, stability boundary surface, scattered data interpolation, twin rotor model helicopter.

"Sorumlu yazar: gurkan.kavuran@ozal.edu.tr

Geliş Tarihi: 24.12.2019, Kabul Tarihi: 08.05.2020 


\section{Giriş}

Çevremizdeki çoğu gerçek sistem yapısında dâhili veya harici çeşitli doğrusalsızlıklar barındırmaktadır. Sistem dinamiği ve kontrol bilimi, sistemlerin istenilen referans girdiyi takip etme kabiliyetini arttırmak için modelleme ve kontrolör tasarım aşamalarının doğru yapılması gerektiğini ortaya koymuştur. Mühendisler sistemleri doğru şekilde modelledikten sonra, bu sistemlere uygun kontrolör tasarımını yaparak sistem tepkisini istenilen düzeye çekerler. Genellikle doğrusallaştırma işlemlerinin yapılarak oluşturulduğu bu modeller, belirli çalışma şartları altında uygun cevabı verirler. Günümüzde doğrusal kontrolör sınıfında olan Oransal-İntegral-Türev (PID) tipi kontrolörler, çoğu uygulamada kullanılmaya devam etmektedir. Tasarım kolaylığı ve uygulama esnekliği olan bu kontrolörün, endüstriyel sistemlerde kullanılmak üzere birçok versiyonu geliştirilmiştir. Kontrol döngülerinin çoğunda PID kontrolörlerinin kullanılmasına rağmen, sistem vibrasyonununa ve çeşitli gürültülere sebep verdiğinden türevsel operatörün saf dışı bırakıldığı PI kontrolörlerin tercih edildiği görülmektedir [1].

Doğrusal sistemlerin yanı sıra doğrusal kontrolörler de çeşitli tasarım aşamalarını içermektedir. Sistemlerinin iyi modellenmesi gerekliliği olduğu gibi, kontrolör parametrelerinin de doğru şekilde hesaplanması gerekmektedir. Uzun yıllar boyunca mühendislerin aşina olduğu PID kontrolör yapısındaki parametrelerin belirlenmesi hususunda birçok araştırma yapılmış ve yöntemler geliştirilmiştir. PID tipi kontrolör yapılarının ayarlanması ile ilgili en popüler yöntemler ZieglerNichols, Cohen-Coon ve Aström-Hagglund'in çalışmalarını içerir [2-4]. Dâhili Model Kontrol (IMC), PID tipi kontrol cihazlarının ayar parametrelerini belirlemek için yaygın olarak kullanılan diğer tasarım yöntemidir [5, 6]. İntegral performans kriterlerine dayalı tasarım yöntemleri çok bilinen yaklaşımlar arasındadır [7]. Ho ve arkadaşlarının çalışmalarından sonra tüm stabilize PI veya PID kontrolörlerinin elde edilmesine büyük ilgi duyulmuştur [8]. Munro ve Söylemez, tüm stabilize PID kontrolörünün parametrelerinin hızlı bir şekilde hesaplanmasıyla ilgili alternatif bir yöntem önermiştir [9]. Shafiei ve Shenton, Huang ve Wang; tüm stabilize kontrolörleri belirlemek için grafiksel çözümler sunmuşlardır [10]. Tan ve arkadaşları, kararlılık sınır eğrisi (KSE) hesaplamasına dayalı, tüm PI veya PID kontrolör parametrelerinin hesaplanması için grafiksel bir yaklaşım önermiştir [11]. Bunun yanı sıra PID kontrolörlerinin parametre ayarlanmasında, optimizasyon metotlarının kullanıldığı algoritmaları içeren kontrol yapılarından da faydalanılmaktadır.

KSE yöntemine göre, eğri altında kalan bölgedeki herhangi $k_{p}$ ve $k_{i}$ değeri sistemi kararlı yapmaktadır. Ancak hatanın değişimine göre hangi parametrelerin optimal sonuç verdiği bilinmemektedir. Bu çalışmada, KSE altında kalan her nokta, belirli bir frekans aralığında dağınık veri enterpolasyon yöntemine göre belirlenmiştir. Bu noktaların oluşturduğu yüzey artık 3 boyutlu kararlılık sınır yüzeyi (KSY) olarak adlandırılabilir. Çoğunlukla sistem kararlılığını garanti eden bu noktalar kullanılarak, kararlı $k_{p}$ ve $k_{i}$ parametre havuzu oluşturulmuştur. Havuzdaki her bir parametrenin birbiriyle olan kombinasyonu kullanılarak, ITAE kriterine göre referans girdi ile sistem çıkışı arasındaki farkı minimize eden PI parametreleri elde edilmiştir. Böylece hem kararlılık hem de optimallik sağlanmıştır. Benzetim çalışmalarının yanı sıra, çift rotorlu model helikopter sistemi üzerinde önerilen yöntemin geçerliliği test edilmiştir.

Çalışmanın 2. Bölümünde $\mathrm{KSE}$ ve dağınık veri enterpolasyonu ile ilgili temel bilgiler verilmiştir. 3. Bölümde önerilen yöntemin doğruluğu gerek benzetim sonuçları gerekse uygulama çalışmalarıyla ispatlanmıştır. Son bölümde ise sonuçlar verilmiştir.

\section{Materyal ve Metot}

\subsection{Kararlılık Sınır Ĕgrisi}

$\mathrm{Bu}$ bölümde tek-giriş tek çıkışlı doğrusal zamanla değişmeyen sistemin kararlığını sağlayacak PI kontrolör parametrelerinin, KSE yöntemine göre nasıl elde edildiği anlatılmıştır. Şekil 1'de verilen kapalı çevrim sistemde $R(s)$ referans giriş, $E(s)$ sistem hatası, $Y(s)$ ise sistem çıkışıdır. 


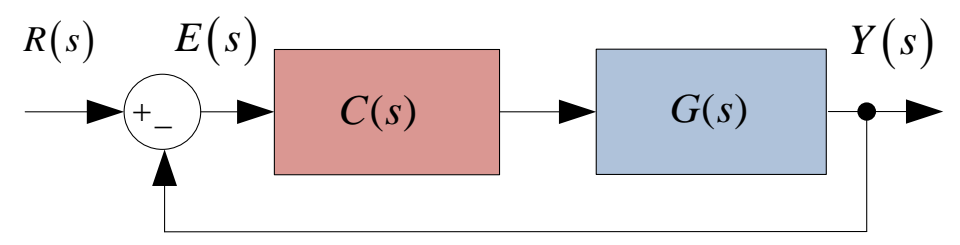

Şekil 1. Geri beslemeli kontrol yapısı

Şekil 1'de gösterilen kontrol edilecek tek girişli tek çıkışlı sistemin geçiş fonksiyonu Denklem 1'de verilmiştir. $C(s)$ ile ifade edilen PI kontrolörün geçiş fonksiyonu ise Denklem 2'deki gibi yazılabilir [11].

$G(s)=\frac{N(s)}{D(s)}$

$C(s)=k_{p}+\frac{k_{i}}{s}$

Sistemin kapalı çevrim karakteristik polinomu Denklem 3 ve 4'teki gibi yazılabilir.

$1+C(s) G(s)=0$

$k_{p}+\frac{k_{i}}{s}=-1 \frac{D(s)}{N(s)}$

Denklem 1'in pay ve payda polinomlarını, tek ve çift olarak ayrı ayrı yazıp, s yerine $j \omega$ konulursa Denklem 5 elde edilir.

$G(j \omega)=\frac{N_{e}\left(-\omega^{2}\right)+j \omega N_{o}\left(-\omega^{2}\right)}{D_{e}\left(-\omega^{2}\right)+j \omega D_{o}\left(-\omega^{2}\right)}$

Denklem 5, Denklem 4'te yerine yazılır ve yeniden düzenlenirse karakteristik polinomun son hali Denklem 6' daki gibi olur.

$$
\Delta(j \omega)=\left[k_{i} N_{e}\left(-\omega^{2}\right)-k_{p} \omega^{2} N_{o}\left(-\omega^{2}\right)-\omega^{2} D_{o}\left(-\omega^{2}\right)\right]+j\left[k_{p} \omega N_{e}\left(-\omega^{2}\right)+k_{i} \omega N_{o}\left(-\omega^{2}\right)+\omega D_{e}\left(-\omega^{2}\right)\right]
$$

Karakteristik polinomun gerçek ve sanal kısımları sıfıra eşitlenirse, Denklem 7 ve 8 elde edilir.

$$
\begin{aligned}
& k_{p}\left(-\omega^{2} N_{o}\left(\omega^{2}\right)\right)+k_{i}\left(N_{e}\left(-\omega^{2}\right)\right)=\omega^{2} D_{o}\left(-\omega^{2}\right) \\
& k_{p}\left(\omega N_{e}\left(-\omega^{2}\right)\right)+k_{i}\left(\omega N_{o}\left(-\omega^{2}\right)\right)=-\omega D_{e}\left(-\omega^{2}\right) \\
& Q(\omega)=-\omega^{2} N_{o}\left(-\omega^{2}\right), R(\omega)=N_{e}\left(-\omega^{2}\right) \\
& S(\omega)=\omega N_{e}\left(-\omega^{2}\right), U(\omega)=\omega N_{o}\left(-\omega^{2}\right) \\
& X(\omega)=\omega^{2} D_{o}\left(-\omega^{2}\right), Y(\omega)=-\omega D_{e}\left(-\omega^{2}\right)
\end{aligned}
$$

Denklem 9 kullanılarak Denklem 7 ve 8 yeniden düzenlenirse Denklem 10 elde edilir.

$$
\begin{aligned}
& k_{p} Q(\omega)+k_{i} R(\omega)=X(\omega) \\
& k_{p} S(\omega)+k_{i} U(\omega)=Y(\omega)
\end{aligned}
$$

Denklem 10'un çözümüyle $k_{p}$ ve $k_{i}$ katsayılarının frekansa bağlı olarak değişimini veren eşitlikler Denklem 11 ve 12 'deki gibi olur. 
$k_{p}=\frac{X(\omega) U(\omega)-Y(\omega) R(\omega)}{Q(\omega) U(w)-R(\omega) S(\omega)}$

$k_{i}=\frac{Y(\omega) Q(\omega)-X(\omega) S(\omega)}{Q(\omega) U(\omega)-R(\omega) S(\omega)}$

Denklem 9, Denklem 11 ve 12'de yerine konulursa, aşağıdaki eşitlikler elde edilir.

$$
\begin{aligned}
& k_{p}=\frac{\omega^{2} D_{o}\left(-\omega^{2}\right) N_{o}\left(-\omega^{2}\right)+D_{e}\left(-\omega^{2}\right) N_{e}\left(-\omega^{2}\right)}{-\left(\omega^{2} N_{o}^{2}\left(-\omega^{2}\right)+N_{e}^{2}\left(-\omega^{2}\right)\right)} \\
& k_{i}=\frac{\omega^{2} D_{e}\left(-\omega^{2}\right) N_{o}\left(-\omega^{2}\right)-\omega^{2} D_{o}\left(-\omega^{2}\right) N_{e}\left(-\omega^{2}\right)}{-\left(\omega^{2} N_{o}^{2}\left(-\omega^{2}\right)+N_{e}^{2}\left(-\omega^{2}\right)\right)}
\end{aligned}
$$

Denklem 13 ve 14 kullanılarak, kararlılık sınır bölgesi $\left(k_{p}, k_{i}\right)$ düzleminde çizilir ve oluşan eğri $\left(k_{p}, k_{i}\right)$ düzlemini kararlı ve kararsız bölgelere böler. Kararlılık bölgesinde seçilebilecek $k_{p}$ ve $k_{i}$ parametreleri sistemi kararlı hale getirecektir [11].

Örnek 1. Şekil 1 ile gösterilen kapalı çevrim sistemde kontrol edilecek sistemin geçiş fonksiyonunu üçüncü dereceden olacak şekilde Denklem 15'deki gibi seçelim.

$G_{1}(s)=\frac{5}{3 s^{3}+2 s^{2}+15 s+2}$

Denklem 15'deki geçiş fonksiyonu için KSE yöntemiyle elde edilen $k_{p}$ ve $k_{i}$ parametrelerinin denklemleri Denklemler 16 ve 17 'de verilmiştir.

$$
\begin{aligned}
& k_{p}(\omega)=\frac{2 \omega^{2}-2}{5} \\
& k_{i}(\omega)=\frac{-3 \omega^{4}+15 \omega^{2}}{5}
\end{aligned}
$$

KSE ve $k_{p}$ ile $k_{i}$ 'nin kararlı (2. bölge) ve kararsız (1. bölge) değerleri için elde edilen kararlılık bölgeleri Şekil 3'te verilmiştir. KSE'nin eksiksiz çizilebilmesi için frekans aralığının doğru seçilmesi gerekmektedir. Bu nedenle açık çevrim sistemin reel ve sanal bileşenlerinin birbirine göre çizimiyle elde edilen ve Şekil 3'te gösterilen Nyquist diyagramı önem arz etmektedir. Nyquist diyagramına göre sistemin doğal frekansı, eğrinin negatif reel ekseni kestiği noktadaki frekans değerine eşittir. Buna göre KSE, $\omega=[0,2.236] \mathrm{rad} / \mathrm{sn}$ aralığında çizdirilmelidir. Şekil 2'ye göre kararsız bölgede seçilen $k_{p}$ ve $k_{i}$ parametrelerinin kullanıldığı kontrollü sistemin zaman cevapları sırasıyla Şekil 4 ve 5 'te verilmiştir. Bu değerlere göre sistem çıkışının kararsız olduğu açıkça görülmektedir. Kararlılık sınır bölgesi içerisinde alınan herhangi $k_{p}$ ve $k_{i}$ değerine göre sistemin zaman cevabı ise Şekil 6'da gösterilmiştir. Kontrolör parametrelerinin $\left[k_{p}, k_{i}\right]=[0.4,3]$ olarak seçilmesiyle sistemin kararlı olduğu gözlemlenmiştir. Ancak seçilen parametre değerlerinin optimal olduğu söylenemez. Bu durum sistemin hata fonksiyonunu minimize edecek şekilde optimal parametre seçimi gerekliliğini ortaya çıkarmıştır. Bunun için eğri altında kalan tüm kararlı $k_{p}$ ve $k_{i}$ değerlerinin belirlenip, parametre havuzunun oluşturulması gerekmektedir. Eğri altında kalan yüzeyin tanımlanması için literatürde birçok yöntem geliştirilmiştir. $\mathrm{Bu}$ çalışmada ise KSE altında kalan her bir kararlı $k_{p}, k_{i}$ değerinin bulunması için üçgenler ağında lineer enterpolasyon yönteminden faydalanılmıştır. 


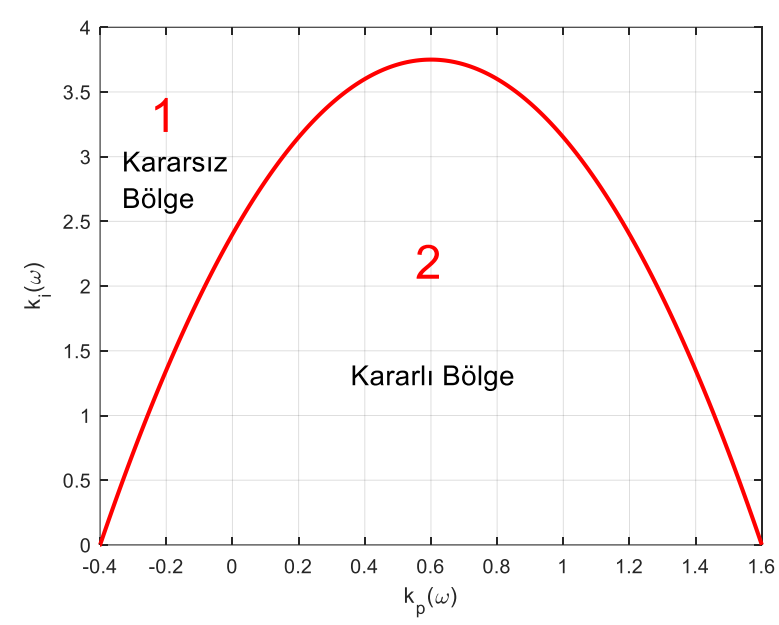

Şekil 2. $G_{1}(s)$ sistemi için elde edilen KSE

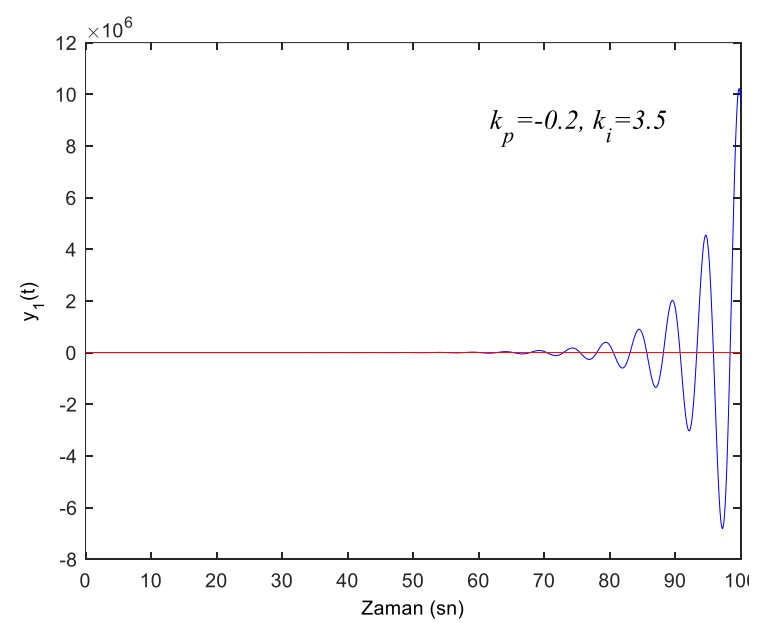

Şekil 4. $\left[k_{p}, k_{i}\right]=[-0.2,3.5]$ için $G_{1}(s)$ sisteminin kararsiz zaman cevabı

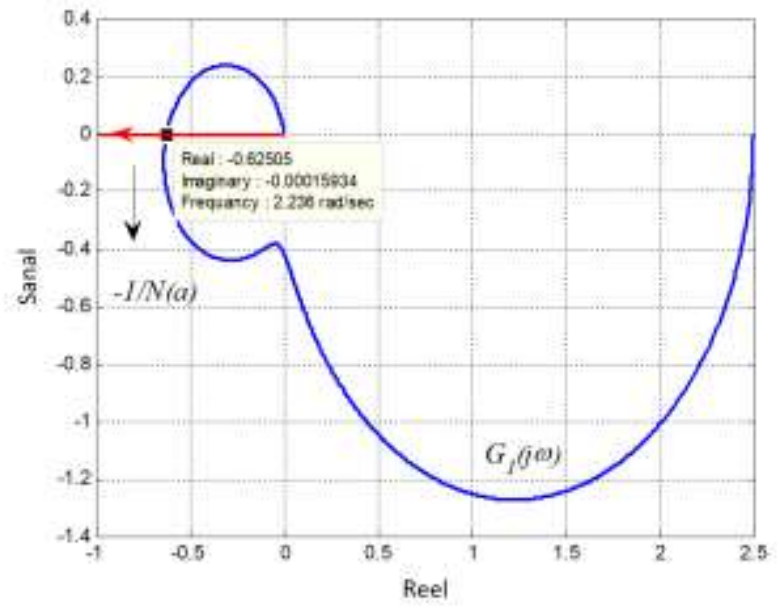

Şekil 3. $G_{1}(s)$ sisteminin Nyquist eğrisi

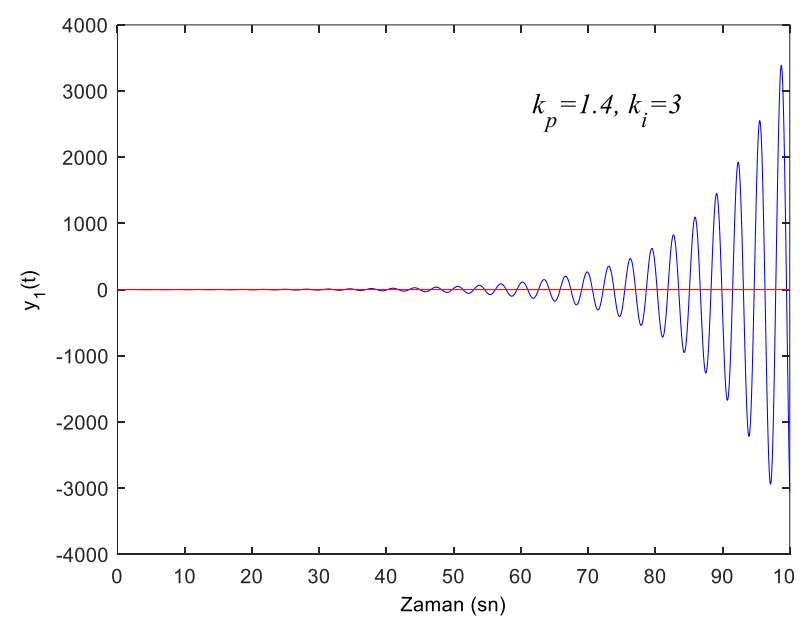

Şekil 5. $\left[k_{p}, k_{i}\right]=[1.4,3]$ için $G_{1}(s)$ sisteminin kararsız zaman cevabı

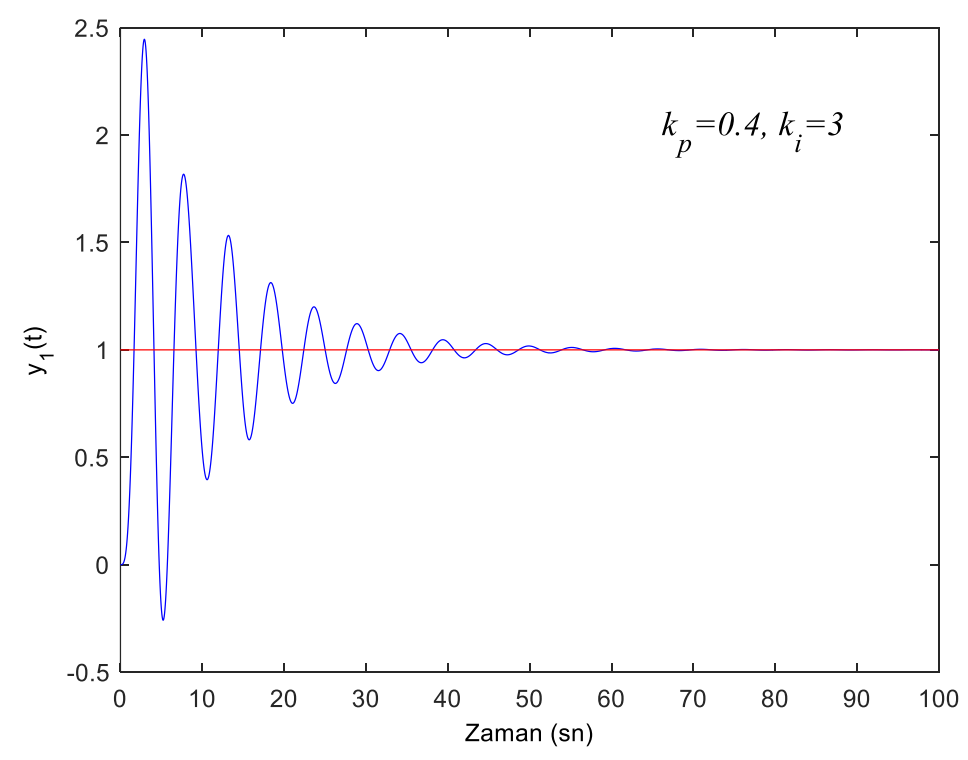

Şekil 6. $\left[k_{p}, k_{i}\right]=[0.4,3]$ için $G_{1}(s)$ sisteminin kararlı zaman cevabı 


\section{2. Üçgenler Ağında Lineer Enterpolasyon (Delaunay Üçgenleme Yöntemi)}

Bölüm 2.1'de bahsedilen KSE altında kalan her bir kararlı $k_{p}$ ve $k_{i}$ değerlerinin bulunması için yüzeyin matematiksel olarak tanımlanması gerekmektedir. Düzenli bir yüzey olan bu alan, basit matematiksel bir fonksiyonla ifade edilebilen, belirli sınırlar içerisinde kalan sabit doğrultulu ve eğimli noktalar kümesidir. Noktalar kümesinin oluşturduğu düzlem yüzeyleri bilinen bir geometrik şekle sahip değildirler. Bu nedenle bu yüzeylerin anlamlı geometrik şekillere bölerek gerçek yüzeyin temsili şeklini oluşturmamız gerekir. Bunun için de en yaygın olarak üçgen, kare ve dikdörtgen tercih edilir. Dağınık veri enterpolasyonu problemi olarak da bilinen düzensiz aralıklı verilerden enterpolasyon ihtiyacı tıbbi görüntüleme, meteorolojik veya jeolojik modelleme, haritac1lık ve bilgisayar destekli geometrik tasarım gibi birçok farklı alanda ortaya çıkmaktadır [12].

Düzensiz üçgen ağı da denilen üçgenleme yöntemleri günümüzde yüzey modellemede yaygın olarak kullanılmaktadır. Bu yöntemin amacı söz konusu olan yüzeyi üçgenlere bölerek üçgen elemanlarından oluşan bir bütün halinde göstermektir. Üçgenler halinde gösterilen yüzeyin iç bölgesinde kalan noktaların belirlenmesi için lineer enterpolasyon yönteminden faydalanılmaktadır. Kullandığımız üçgenlerin içinde kalan kestirim noktalarına ait yükseklikler, kullandığımız üçgenlerin köşe noktalarının yükseklikleri yardımıyla bazı fonksiyonlar kullanılarak hesaplanmaktadır. Bunun için kullanılan literatürdeki en etkin üçgenleme algoritması, Delaunay tarafindan önerilmiştir [13]. Bu yöntemde tanımlanmak istenen yüzey, rastgele ya da düzgün olarak dağılmış bulunan dayanak noktalarının birleştirilmesi ile düzlem üçgenlerden oluşan çok yüzlü bir yüzeyle kaplanır.

Dağınık noktaların, 2 boyutlu $\left(x_{i}, y_{i}\right)$ düzleminde olduğu durumu göz önünde bulundurursak, bu noktaların almış olduğu değerler $z_{i}$ kadar yükseklikte konumlandırılırsa oluşan üçgene ait köşeler, $\left(x_{1}, y_{1}, z_{1}\right),\left(x_{2}, y_{2}, z_{2}\right)$ ve $\left(x_{3}, y_{3}, z_{3}\right)$ olmak üzere, 3 noktayla tanımlanan düzlem denklemi Denklem 18 'deki gibi olmaktadır [14].

$z=a x+b y+c$

Bilinen üç noktadan her birinin $\mathrm{x}, \mathrm{y}, \mathrm{z}$ değerlerini bu denklemde yerine konulursa, doğrusal bir denklem takımı elde edilir.

$$
\begin{aligned}
& z_{1}=a x_{1}+b y_{1}+c \\
& z_{2}=a x_{2}+b y_{2}+c \\
& z_{3}=a x_{3}+b y_{3}+c
\end{aligned}
$$

Denklem 19'daki a, b, c katsayıları, denklem sisteminin çözümüyle bulunabilir. Bu katsayılar bilindiğinde, Denklem 18 bize bu üçgenin içinde yer alan herhangi bir $P$ noktası $\mathbf{x}=(x, y)$ için $\mathrm{z}$ enterpolasyon değerini verir. Ayrıca üçgen içindeki herhangi bir $P$ noktasındaki $z$ değeri, barycentric enterpolasyon ile de bulunabilir. $P_{1}, P_{2}$ ve $P_{3}$ ile ifade edilen üçgen köşeleri, $\mathbf{x}_{1}=\left(x_{1}, y_{1}\right)$, $\mathbf{x}_{2}=\left(x_{2}, y_{2}\right)$ ve $\mathbf{x}_{3}=\left(x_{3}, y_{3}\right)$ noktalarıla tanımlanacak olursa, $(x, y)$ düzlemindeki herhangi bir $P$ noktasının konumu, bu üç köşenin konumlarının ağırlıklı ortalaması olarak Denklem 20 ile ifade edilebilir.

$\mathbf{x}=a_{1} \mathbf{x}_{1}+a_{2} \mathbf{x}_{2}+a_{3} \mathbf{x}_{3}$

Burada, $a_{1}+a_{2}+a_{3}=1, a_{i}>0, i=1,2,3 \ldots$ olmak zorundadır. Ağırlıklar, $P$ noktasının baryentric koordinatları olarak adlandırılır. Denklem 20'yi doğrusal bir fonksiyon şeklinde ifade edecek olursak Denklem 21 elde edilir.

$$
g(\mathbf{x})=a_{1} g\left(\mathbf{x}_{1}\right)+a_{2} g\left(\mathbf{x}_{2}\right)+a_{3} g\left(\mathbf{x}_{3}\right)
$$




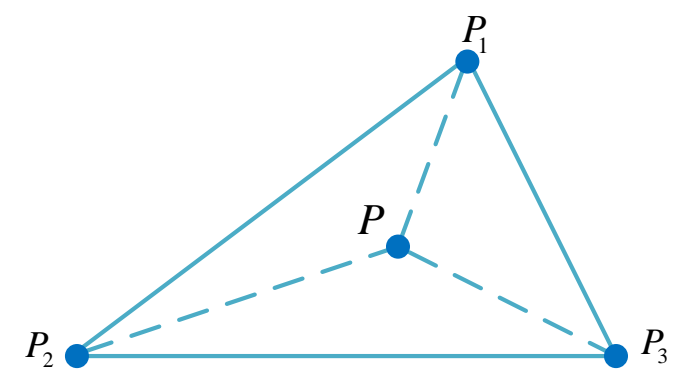

Şekil 7. $P_{1} P_{2} P_{3}$ üçgeni

Enterpolasyon fonksiyonu $z=\hat{f}(x, y)$ lineer olduğu için, $P$ noktasındaki $z$ değeri Eşitlik 22 ile ifade edilen, $P_{i}$ köşelerinin bulunduğu lokasyonlardaki $z_{i}$ değerlerinin ağırlıklı ortalamasıdır;

$$
z=a_{1} z_{1}+a_{2} z_{2}+a_{3} z_{3}
$$

Eşitlikte 20'de olduğu gibi $a_{1}+a_{2}+a_{3}=1$ 'dir. $P, P_{1}, P_{2}$ ve $P_{3}$ noktalarının yerleri bilindiği için, $a_{1}, a_{2}, a_{3}$ ağırlıkları, Eşitlik 23 ile tanımlanan doğrusal sistem takımı çözülerek bulunabilir [14].

$$
\begin{aligned}
& a_{1} x_{1}+a_{2} x_{2}+a_{3} x_{3}=x \\
& a_{1} y_{1}+a_{2} y_{2}+a_{3} y_{3}=y \\
& a_{1}+a_{2}+a_{3}=1
\end{aligned}
$$

Bu denklem takımının çözümü Eşitlik 24’te verilmiştir.

$$
\left(\begin{array}{l}
a_{1} \\
a_{2} \\
a_{3}
\end{array}\right)=\left(\begin{array}{ccc}
x_{1} & x_{2} & x_{3} \\
y_{1} & y_{2} & y_{3} \\
1 & 1 & 1
\end{array}\right)^{-1}\left(\begin{array}{l}
x \\
y \\
1
\end{array}\right)
$$

Ayrıca Cramer kuralı kullanılarak da çözüm yapılabilir. Bunun için Eşitlik 25 ve 26'dan faydalanılmaktadır [14].

$$
a_{1}=D_{1} / D, a_{2}=D_{2} / D, a_{3}=D_{3} / D
$$

Burada,

$$
D=\left|\begin{array}{ccc}
x_{1} & x_{2} & x_{3} \\
y_{1} & y_{2} & y_{3} \\
1 & 1 & 1
\end{array}\right|, \quad D_{1}=\left|\begin{array}{ccc}
x & x_{2} & x_{3} \\
y & y_{2} & y_{3} \\
1 & 1 & 1
\end{array}\right|, \quad D_{2}=\left|\begin{array}{ccc}
x_{1} & x & x_{3} \\
y_{1} & y & y_{3} \\
1 & 1 & 1
\end{array}\right|, \quad D_{3}=\left|\begin{array}{ccc}
x_{1} & x_{2} & x \\
y_{1} & y_{2} & y \\
1 & 1 & 1
\end{array}\right|
$$

KSE altında kalan her bir kararlı $k_{p}, k_{i}$ değeri, Eşitlik 24'ün çözümüyle elde edilerek kararlı parametre havuzu oluşturulabilir. Sonraki bölümde her bir parametrenin test edilmesiyle, sistemi kararlı yapacak optimal değerler bulunacaktır.

\section{Bulgular ve Tartışma}

\subsection{Benzetim Çalışması}

Bu bölümde, Bölüm 2.1 ve 2.2 'de anlatılan yöntemler kullanılarak tasarımı yapılan PI kontrolörün performans1, Matlab ortamında oluşturulan geçiş fonksiyonu kullanılarak incelenecektir. Bunun için Örnek 2'de verilen iki kutuplu ve tek sıfırlı $G_{2}$ sistemi kullanılacaktır. 
Örnek 2. Şekil 1 ile gösterilen kapalı çevrim sistemde kontrol edilecek sistemin geçiş fonksiyonunu Denklem 27'deki gibi seçelim.

$G_{2}=\frac{-0.2791 s+26.46}{s^{2}+11.4 s+27.04}$

Bu sistem için Denklem 13 ve 14 'e göre $k_{p}(\omega)$ ve $k_{i}(\omega)$ fonksiyonları aşağıdaki gibi elde edilir.

$k_{p}(\omega)=\frac{200\left(14784587 \omega^{2}-357739200\right)}{7789681 \omega^{2}+70013160000}$
$k_{i}(\omega)=\frac{400\left(-69775 \omega^{2}-75577816 \omega^{2}\right)}{7789681 \omega^{2}+70013160000}$

Eşitlik 27 ile verilen sistem için $k_{p}$ ve $k_{i}$ 'nin kararlı ve kararsı değerlerini içeren KSE Eşitlik 28 ve 29 kullanılarak Şekil 9'daki gibi elde edilmiştir. KSE'nin çizimi için gerekli olan frekans aralığı, açık çevrim sistemin reel ve sanal bileşenlerinin birbirine göre çizimiyle elde edilen ve Şekil 8'de gösterilen Nyquist diyagramına göre $\omega=[0,32.911] \mathrm{rad} / \mathrm{sn}$ 'dir. Elde edilen KSE, Bölüm 2.2' de önerilen yönteme göre Şekil 10'daki KSY'ne dönüşmektedir.

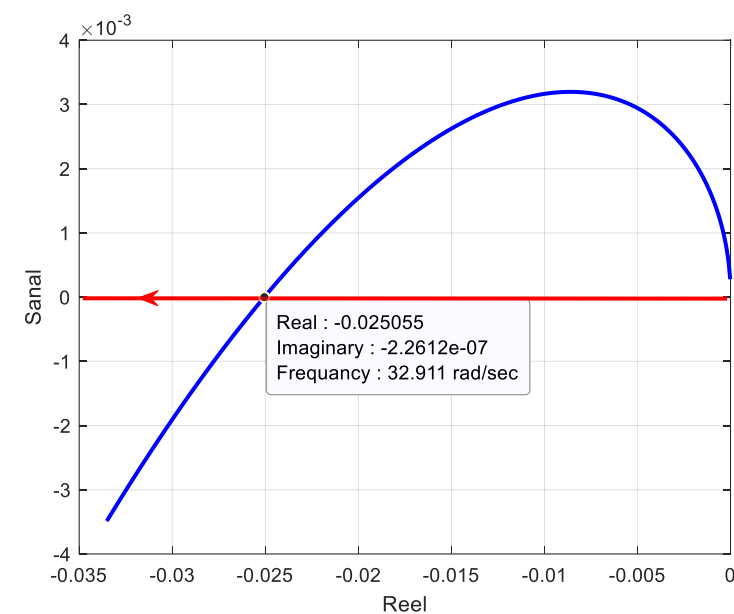

Şekil 8. $G_{1}(s)$ sisteminin Nyquist eğrisi

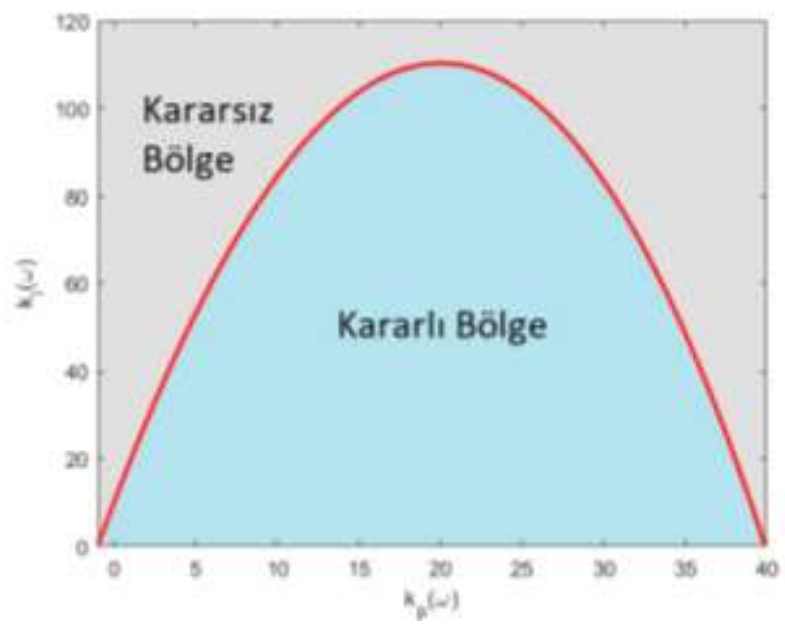

Şekil 9. $G_{2}(s)$ sistemi için elde edilen KSE

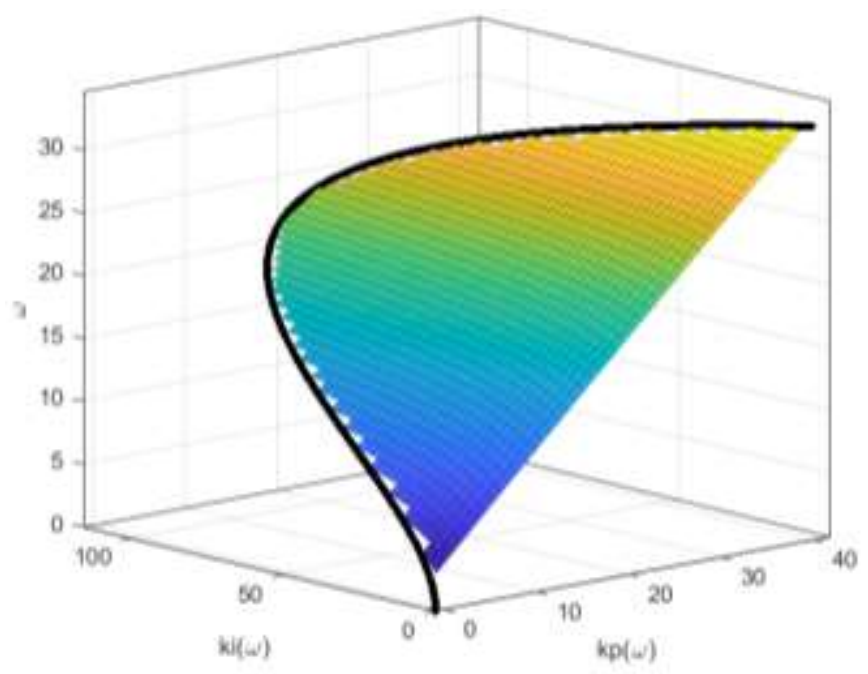

Şekil 10. $G_{2}(s)$ sistemi için elde edilen KSY 
Bu yüzeyi tanımlayan tüm noktalar kontrollü kapalı çevrim sistemi kararlı yapmaktadır. Ancak hangi noktaların optimal sonuç verdiği bilinmemektedir. Bu nedenle Şekil 11'de verilen yapı kullanılarak, eğri altında kalan her nokta iteratif olarak test edilmiştir. KSY havuzu belli olduğu için kararlı ve optimal noktaların seçimi, minimum hatanın oluştuğu duruma göre otomatik olarak yapılacaktır. Matlab/Simulink bloklarıyla senkron çalışan kod rutini kullanılarak kararlılık sınır bölgesi içerisindeki optimal $k_{p}$ ve $k_{i}$ değerleri sırasıyla 3.497 ve 9.271 olarak bulunmuştur. Bu noktalardaki kontrollü sistemin zaman cevabı Şekil 12'de verilmiştir. Elde edilen ITAE değeri ise 0.046 'dır. Böylelikle sistemin hata fonksiyonunu minimize edecek optimal parametre değerleri, belirlenen parametre havuzu kullanılarak elde edilmiştir.

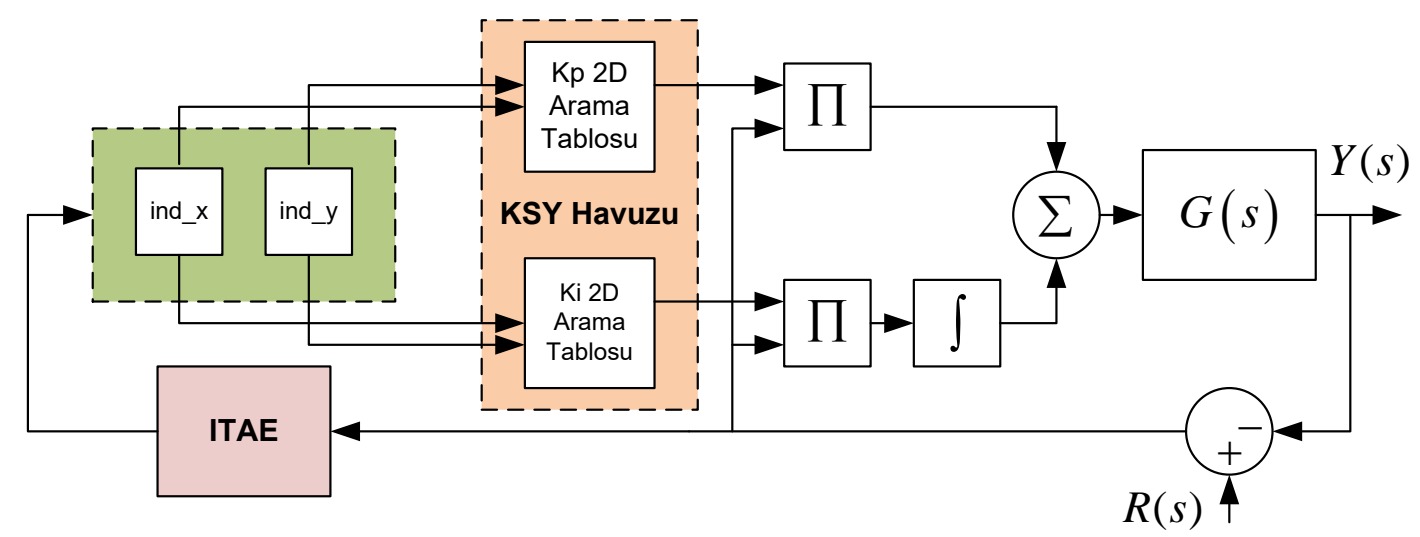

Şekil 11. Önerilen sistemin blok diyagramı

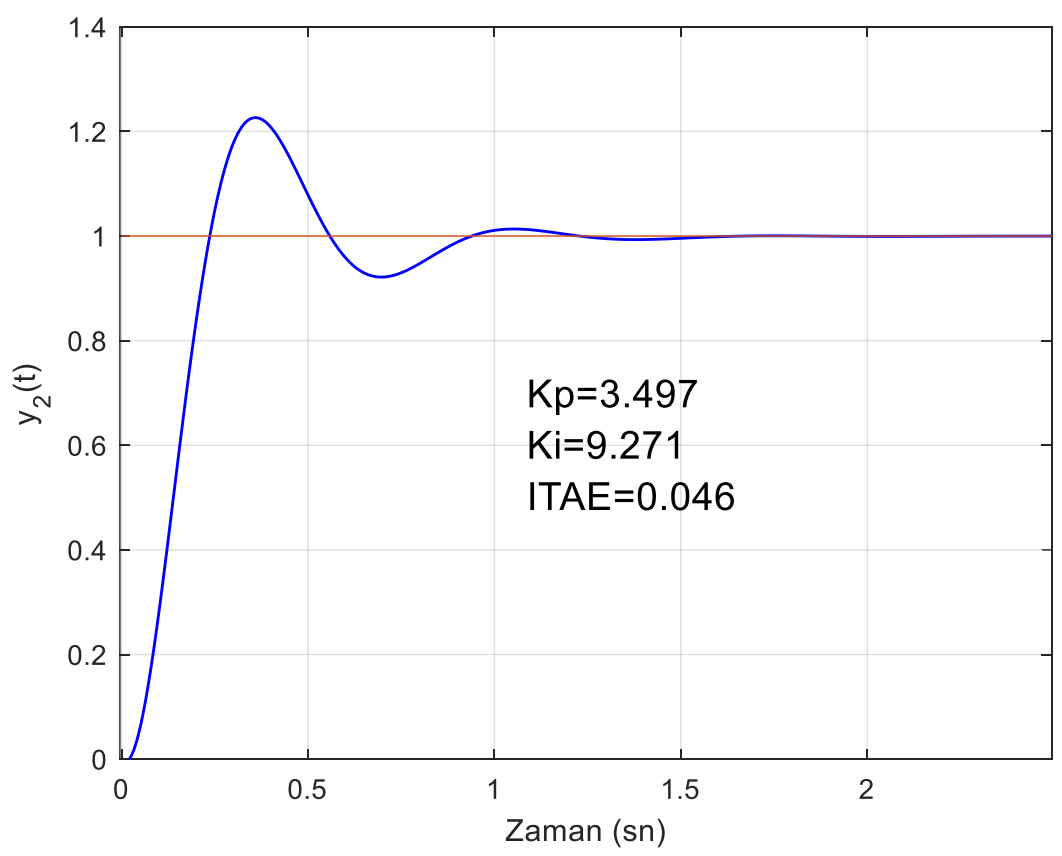

Şekil 12. Optimal $\left[k_{p}, k_{i}\right]=[3.497,9.271]$ değerleri için $G_{2}(s)$ sisteminin kararlı zaman cevabı

\subsection{Deneysel Çalışma}

Bir önceki bölümde, önerilen yöntemin doğruluğu benzetim çalışması üzerinden ispatlanmıştır $\mathrm{Bu}$ bölümde ise laboratuvar ortamında uçuş dinamiklerinin incelenmesine imkân sağlayan çok girişli-çok çıkışlı model helikopterin eğim açısı kontrolü gerçek zamanlı incelenecektir. Bilindiği üzere bir helikopter, ana rotor ve kuyruk rotoru olmak üzere iki rotora sahiptir. Ana rotor, ileri, yan ve dikey gidiş için gerekli torku sağlarken, kuyruk rotoru ise ana rotorun oluşturduğu tork etkisini dengelemeyi ve sapma hareketi yapmasını sağlar [15]. Sistemin yatay ve düşey eksendeki hareketini modelleyebilmek 
için bu iki rotora bağlı olan eğim ve sapma açılarından faydalanılmaktadır. Denetleyicinin iyi bir şekilde tasarlanabilmesi için sistem dinamiğinin iyi anlaşılması ve modellenmesi gerekmektedir. Bir helikopter, mekanik yasalar kullanılarak veya deneysel olarak helikopter üzerinden veri toplayarak modellenebilir [16]. Genelde doğrusal olmayan helikopter modeli mekanik yasalar kullanılarak oluşturulurken, sistem tanılama ile doğrusal ve düşük mertebeden modeller elde edilir [15]. Eğim ve sapma hareketinin benzetimi Bölüm 2.1 ve 2.2'de ayrıntılı bir şekilde açılanacaktır. Çalışmada kullanılan helikopter modeline ait mekanik yapı ise Şekil 1'de gösterilmiştir [17].

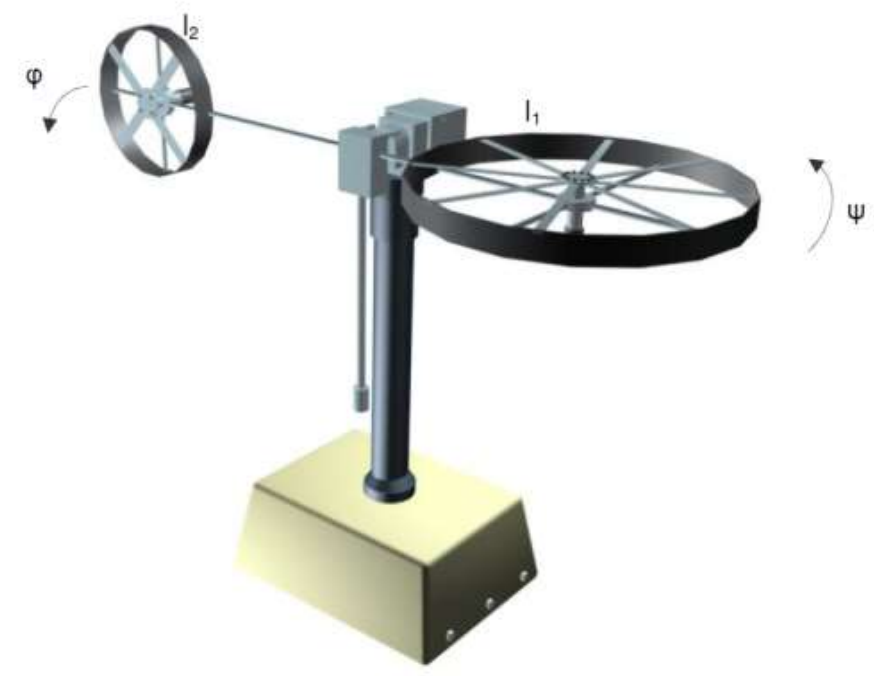

Şekil 13. Çift rotorlu ÇGÇÇ helikopter modeli

Çevremizdeki çoğu gerçek sistem doğrusal değildirler. Sistem durum değişkenlerinden en az biri doğrusal olmayan bir fonksiyonun argümanıdır. Şekil 13'te verilen elektro-mekanik sistem için doğrusal olmayan model denklemleri elde edilebilir. Mekanik yapı söz konusu olduğunda, dikey hareket için aşağıdaki momentum denklemleri elde edilir. Eğim hareketini ifade eden temel eşitlikler Denklem 30-31'de verilmiştir. Bu eşitlikler dikey hareket için kullanılan açısal momentumu oluşturan, yer çekimi, sürtünme kuvveti ve jiroskobik momentumun toplamıla elde edilir [17].

$$
\begin{aligned}
& \ddot{\psi}=\frac{a_{1}}{I_{1}} \tau_{1}^{2}+\frac{b_{1}}{I_{1}} \tau_{1}-\frac{M_{g}}{I_{1}} \sin (\psi)+\frac{0.0326}{2 I_{1}} \sin (2 \psi)(\dot{\varphi})^{2}-\frac{B_{1 \psi}}{I_{1}} \dot{\psi}-\frac{k_{g y}}{I_{1}} \cos (\psi)\left(a_{1} \tau_{1}^{2}+b_{1} \tau_{1}\right) \dot{\varphi} \\
& \dot{\tau}_{1}=-\frac{T_{10}}{T_{11}} \tau_{1}+\frac{k_{1}}{T_{11}} u_{\psi}
\end{aligned}
$$

Eşitlik 30-31 ile verilen dikey hareketi modelleyen denklemler, yatay eksendeki hareketi tanımlamak için de kullanılmaktadır. Buna göre sapma hareketini ifade eden eşitlikler Denklem 32-33'te verilmiştir $[1,8]$.

$$
\begin{aligned}
& \ddot{\varphi}=\frac{a_{2}}{I_{2}} \tau_{2}^{2}+\frac{b_{2}}{I_{2}} \tau_{2}-\frac{B_{1 \varphi}}{I_{2}} \dot{\varphi}-\frac{1.75}{I_{2}} k_{c}\left(a_{1} \tau_{1}^{2}+b_{1} \tau_{1}\right) \\
& \dot{\tau}_{2}=-\frac{T_{20}}{T_{21}} \tau_{2}+\frac{k_{2}}{T_{21}} u_{\varphi}
\end{aligned}
$$

Burada sırasıyla $\psi$ ve $\varphi$ eğim ve sapma açısı, $\dot{\psi}$ ve $\dot{\varphi}$ açısal hız, $\tau_{1}$ ve $\tau_{2}$ ana ve kuyruk motorlarının moment ifadesi, $u_{\psi}$ ve $u_{\varphi}$ ise motorlara uygulanan gerilim değeri veya kontrol işaretidir. Sisteme ait katsayllar Tablo 1'de verilmiştir [17]. 
Tablo 1. Sistem Parametreleri

\begin{tabular}{cll}
\hline & \multicolumn{1}{c}{ Parametreler } & \multicolumn{1}{c}{ Değerler } \\
\hline$B_{1 \psi}$ & Dikey eksen sürtünme kats. & $6 \times 10^{-3} \mathrm{Nms} / \mathrm{rad}$ \\
$B_{1 \varphi}$ & Yatay eksen sürtünme kats. & $1 \times 10^{-1} \mathrm{Nms} / \mathrm{rad}$ \\
$I_{1}$ & Dikey rotorun atalet momenti & $6.8 \times 10^{-2} \mathrm{~kg} \cdot \mathrm{m}^{2}$ \\
$I_{2}$ & Yatay rotorun atalet momenti & $2 \times 10^{-2} \mathrm{~kg} \cdot \mathrm{m}^{2}$ \\
${ }^{*} b_{1}$ & Statik karakteristik parametre & 0.0924 \\
${ }^{*} b_{2}$ & Statik karakteristik parametre & 0.09 \\
${ }^{*} a_{1}$ & Statik karakteristik parametre & 0.0135 \\
${ }^{*} a_{2}$ & Statik karakteristik parametre & 0.02 \\
& & \\
${ }^{\tau}{ }_{1}$ & Ana motor torku & $\tau_{1}=\frac{k_{1}}{T_{11} s+T_{10}} u_{\psi}$ \\
& & \\
& & $\tau_{2}=\frac{k_{2}}{T_{21} s+T_{20}} u_{\varphi}$ \\
$\tau_{2}$ & Kuyruk motor torku & 1.1 \\
& & 0.8 \\
${ }^{*} k_{1}$ & Ana motor kazanc1 & $1.2 \mathrm{~s}$ \\
${ }^{*} k_{2}$ & Kuyruk motor kazancı & $1.1 \mathrm{~s}$ \\
$T_{10}$ & Ana motor payda değeri & $1 \mathrm{~s}$ \\
$T_{11}$ & Ana motor payda değeri & $1 \mathrm{~s}$ \\
$T_{21}$ & Kuyruk motoru payda değeri & 0.05 \\
$T_{20}$ & Kuyruk motoru payda değeri & -0.2 \\
${ }^{*} k_{g y}$ & Jiroskobik moment katsayis1 & $0.32 \mathrm{~N} . \mathrm{m}$ \\
${ }^{*} k_{c}$ & Çapraz etki kazanc1 & \\
$M_{g}$ & Yerçekimi momenti & \\
\hline
\end{tabular}

Böyle bir modeli transfer fonksiyonu cinsinden sunabilmek için doğrusallaştırılması gerekmektedir. Model helikopterin yatay eksende yaptığ 1 hareketi temsil eden transfer fonksiyonu, Eşitlik 30-31 ile verilen doğrusal olmayan denklemler üzerinden gidilerek elde edilmiştir. Doğrusal olmayan model girişine farklı sinyallerin toplamından oluşan değişken bir işaret uygulanmış ve çıkış dalga şekilleri incelenmiştir. Uygun sinırlarda tutulan bu sinyaller, MATLAB System Identification Toolbox yardımıyla işlenerek, yaklaşık sistemin parametre kestiriminde kullanılmıştır. Üçüncü mertebeden sıfırı olmayan bir sistem modeli alınarak, katsayılar güncellenmiştir. Buna göre elde edilen sistemin transfer fonksiyonu aşağıdaki gibidir. Burada pay ve payda polinomlarının $s^{0}$ 'lı katsayıları çok küçük olduğu için ihmal edilebilir.

$$
G(s)_{\psi} \approx \frac{0.009664 s^{3}-0.03481 s^{2}+1.613 s+3.669 \times 10^{-5}}{s^{4}+0.9794 s^{3}+4.64 s^{2}+4.051 s-5.988 \times 10^{-7}}
$$

Şekil 14'te sistem tanılamada kullanılan giriş işareti verilmiştir. Rastgele, basamak ve sinüsoidal sinyallerin toplamından oluşan bu işaret, öngörülen sistem için birçok harmoniği barındırmaktadır. Şekil 15 'te ise Eşitlik 34 ve Eşitlik 30-31'de verilen sistemlerin çıkış dalga şekilleri görülmektedir. Yaklaşık olarak \%95.17'lik başarımla gerçek sistemi takip eden $G(s)_{\psi}$, KSY tabanlı PI kontrolör tasarımı için rahatlıkla kullanılabilir seviyededir. 


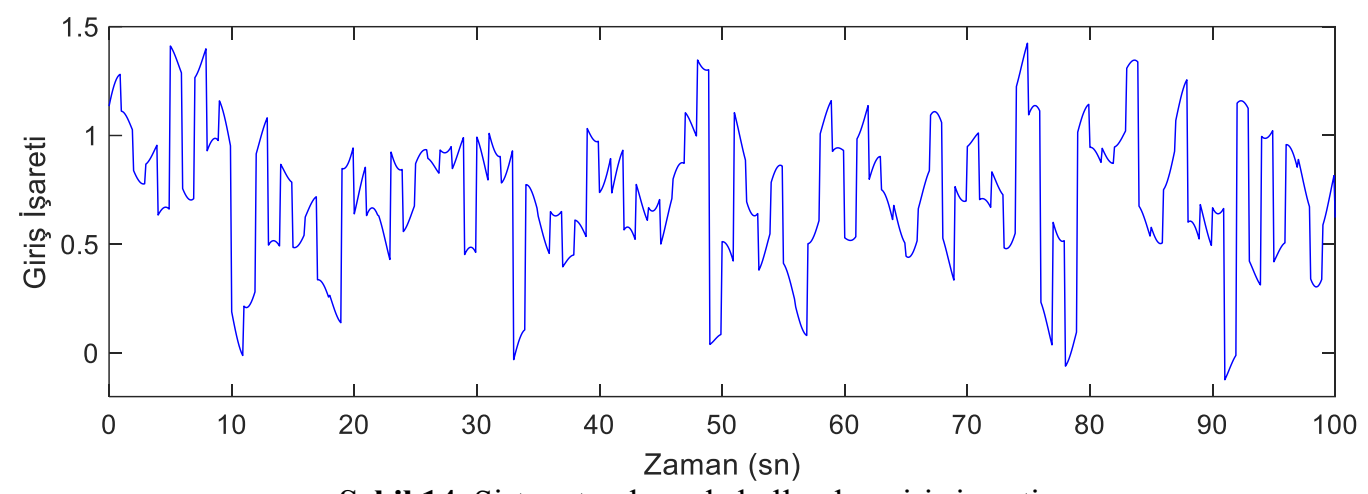

Şekil 14. Sistem tanılamada kullanılan giriş işareti

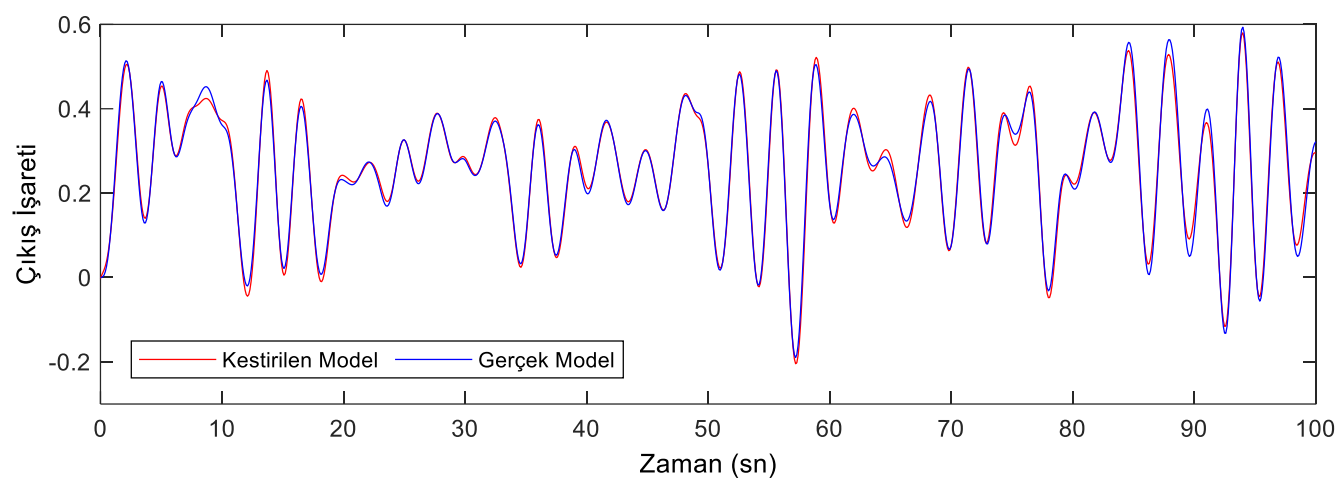

Şekil 15. Kestirilen model ve gerçek sistem çıkışları

Bu sistem için Denklem 13 ve 14'e göre $k_{p}(\omega)$ ve $k_{i}(\omega)$ fonksiyonları aşağıdaki gibi elde edilir.

$$
\begin{aligned}
& k_{p}(\omega)=\frac{-400\left(27671826 \omega^{4}-1112774665 \omega^{2}+4083914375\right)}{23348224 \omega^{4}-7491081975 \omega^{2}+650442250000} \\
& k_{i}(\omega)=\frac{-500\left(4832000 \omega^{6}-845966937 \omega^{4}+3812667655 \omega^{2}\right)}{23348224 \omega^{4}-7491081975 \omega^{2}+650442250000}
\end{aligned}
$$

Eşitlik 34 ile verilen sistem için $k_{p}$ ve $k_{i}$ 'nin kararlı ve kararsız değerlerini içeren KSE Eşitlik 35 ve 36 kullanılarak Şekil 16'daki gibi elde edilmiştir. KSE'nin çizimi için gerekli olan frekans aralığı, açık çevrim sistemin reel ve sanal bileşenlerinin birbirine göre çizimiyle elde edilen Nyquist diyagramına göre $\omega=[0,2.15] \mathrm{rad} / \mathrm{sn}$ 'dir. KSE eğrisi altında kalan noktalar, Bölüm 2.2'de önerilen yönteme göre Şekil 17'deki gibi elde edilmiştir.

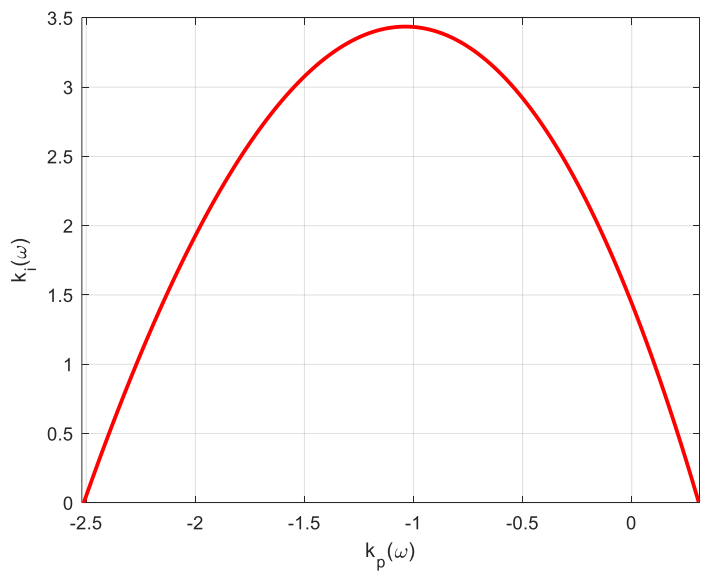

Şekil 16. $G(s)_{\psi}$ sistemi için elde edilen KSE

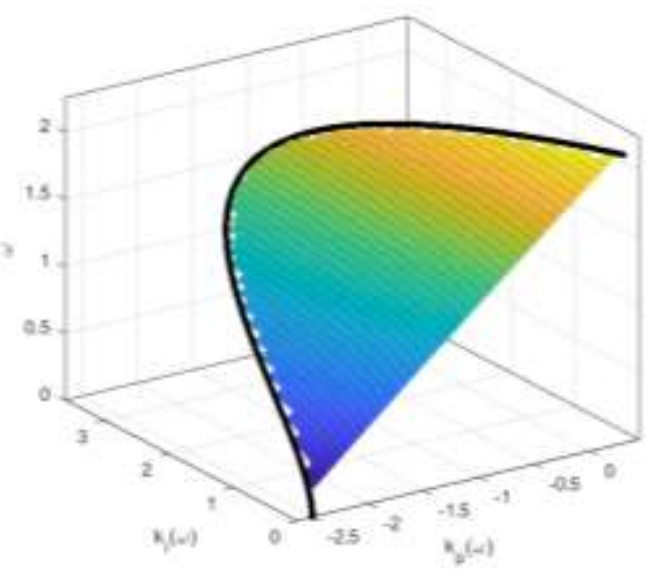

Şekil 17. $G(s)_{\psi}$ sistemi için elde edilen KSY 
Şekil 18 ve 19 'da sırasıyla, $\left[k_{p}, k_{i}\right]=[0.1,0.5]$ ve $\left[k_{p}, k_{i}\right]=[-1,0.8]$ değerleri için gerçek sistemin kararlı eğim açısı değişimleri verilmiştir. Bu değerler Şekil 16'da verilen KSE'nin altında kalan alanda yer almaktadır. Şekil 20'de ise eğri dışındaki alanda bulunan $\left[k_{p}, k_{i}\right]=[0.5,0.2]$ değerleri için model helikopterin kararsız eğim açısı değişimi görülmektedir. Eğri altındaki $\left[k_{p}, k_{i}\right]=[0.1232,0.052]$ değerleri için model helikopterin gerçek sistem, kestirilen doğrusal sistem ve doğrusal olmayan sistem modellerinin kararlı eğim açısı değişimi ise Şekil 21'de gösterilmiştir.

Bölüm 2.2'de anlatılan yönteme göre elde edilen Şekil 17'deki KSY kullanılarak, eğri altında kalan kararlı tüm noktalar belirlenmiştir. Şekil 11'de verilen blok diyagram kullanılarak, Eşitlik 34'deki kestirilen doğrusal sistem için optimal PI parametreleri, $\left[k_{p}, k_{i}\right]=[-0.732,1.123]$ olarak elde edilmiştir. Bu değerlerin doğruluğu daha sonra hem gerçek sistem hem de Eşitlik 30-31 ile ifade edilen doğrusal olmayan model üzerinden test edilmiştir. Model helikopterin; gerçek sistem, kestirilen doğrusal sistem ve doğrusal olmayan sistem modellerinin, optimal $\left[k_{p}, k_{i}\right]=[-0.732,1.123]$ değerleri için kararlı eğim açısı değişimi Şekil 22'de görülmektedir.

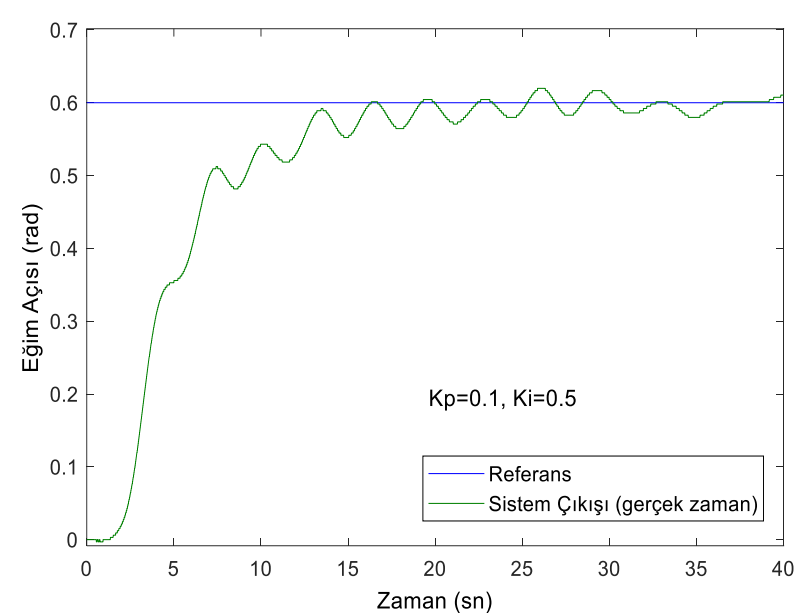

Şekil 18. $\left[k_{p}, k_{i}\right]=[0.1,0.5]$ değerleri için model helikopterin kararlı eğim açısı değişimi

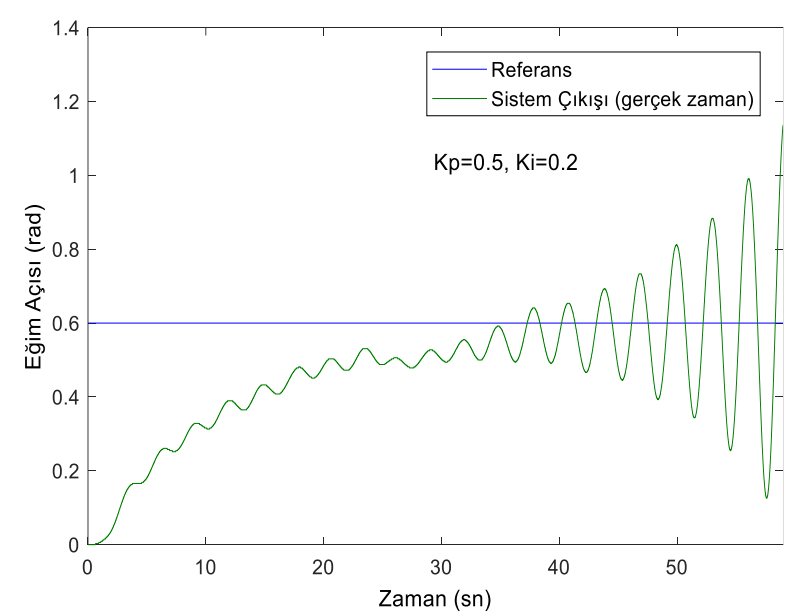

Şekil 20. $\left[k_{p}, k_{i}\right]=[0.5,0.2]$ değerleri için model helikopterin kararsız eğim açısı değişimi

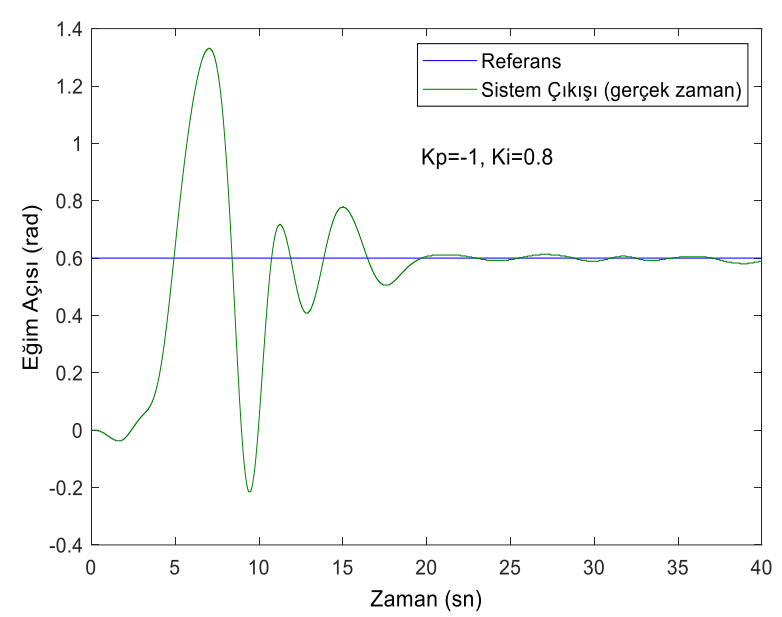

Şekil 19. $\left[k_{p}, k_{i}\right]=[-1,0.8]$ değerleri için model helikopterin kararlı eğim açısı değişimi

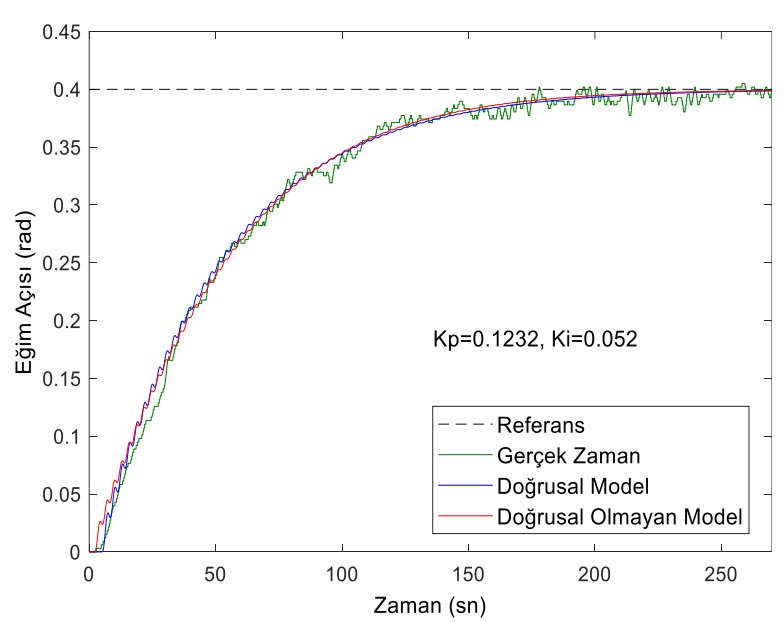

Şekil 21. $\left[k_{p}, k_{i}\right]=[0.1232,0.052]$ değerleri için model helikopterin gerçek sistem, kestirilen doğrusal sistem ve doğrusal olmayan sistem modellerinin kararlı eğim açısı değişimi 


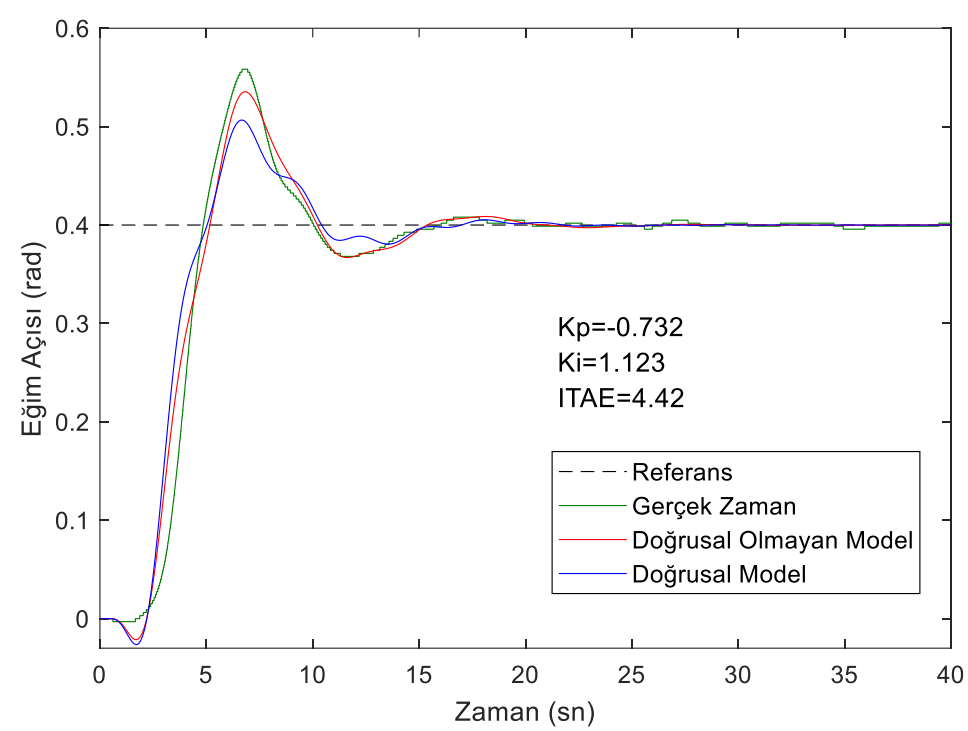

Şekil 22. Model helikopterin; gerçek sistem, kestirilen doğrusal sistem ve doğrusal olmayan sistem modellerinin, optimal $\left[k_{p}, k_{i}\right]=[-0.732,1.123]$ değerleri için kararlı eğim açısı değişimi.

\section{Sonuç ve Öneriler}

$\mathrm{Bu}$ çalışmada PI parametrelerinin hesaplanması için geliştirilen grafiksel yöntemlerden olan KSE metodu, sistemi kararlı yapan optimal $k_{p}$ ve $k_{i}$ değerlerinin bulunması için dağınık veri enterpolasyon yöntemine göre yeniden oluşturulmuştur. Önerilen yöntem sayesinde 3 boyutlu kararlılık sınır yüzeyi çizdirilmiş, sistem kararlılığını garanti noktalar kullanılarak kararlı $k_{p}$ ve $k_{i}$ parametre havuzu oluşturulmuştur. Havuzdaki her bir parametre kullanılarak, referans girdi ile sistem çıkışı arasındaki hatayı minimize eden PI parametreleri elde edilmiştir. Önerilen yöntemin geçerliliği ve doğruluğu Matlab/Simulink ortamında oluşturulan geçiş fonksiyonları üzerinden doğrulanmıştır. Ayrıca laboratuvar ortamında uçuş dinamiklerinin incelenmesine imkân sağlayan çok girişli-çok çıkışlı model helikopterin eğim açısı kontrolü gerçek zamanlı olarak incelenmiştir. Doğrusallaştırılmış model kullanılarak tasarımı yapılan KSY ve PI kontolörün, kararlı bir sistem cevabı verdiği gözlemlenmiştir. Model helikopterin; gerçek sistem, kestirilen doğrusal sistem ve doğrusal olmayan sistem modellerinin, optimal $\left[k_{p}, k_{i}\right]=[-0.732,1.123]$ değerleri için benzer eğim açısına sahip oldukları gösterilmiştir. Sonraki çalışmalarda optimal parametrelerin grafiksel yöntemler kullanılmadan elde edilmesini sağlayacak numerik yöntemlerin geliştirilmesi planlanmaktadır.

\section{Yazarların Katkısı}

Çalışmada tüm katkı tarafıma aittir.

\section{Çıkar Çatışması Beyanı}

Yazarlar arasında herhangi bir çıkar çatışması bulunmamaktadır.

\section{Araştırma ve Yayın Etiği Beyanı}

Yapılan çalışmada araştırma ve yayın etiğine uyulmuştur.

\section{Kaynaklar}

[1] Åström K.J., Hägglund T. 2001. The future of PID control. Control Eng. Pract., 9 (11): 1163 1175 . 
[2] Ziegler J.G., Nichols N.B. 1993. Optimum Settings for Automatic Controllers. J. Dyn. Syst. Meas. Control, 115 (2B): 220-222.

[3] Cohen G.H., Coon G.A. 1953. Theoretical Consideration of Retarded Control. Trans. ASME, 75 (1): 827-834.

[4] Åström K.J., Hägglund T. 1984. Automatic tuning of simple regulators with specifications on phase and amplitude margins. Automatica, 20 (5): 645-651.

[5] Kumar D.B.S., Padma Sree R. 2016. Tuning of IMC based PID controllers for integrating systems with time delay. ISA Trans., 63242-63255.

[6] Li P., Zhu G. 2019. IMC-based PID control of servo motors with extended state observer. Mechatronics, 62102252.

[7] Zhuang M., Atherton D.P. 1993. Automatic tuning of optimum PID controllers. IEE Proc. D Control Theory Appl., 140 (3): 216.

[8] Ho M-T., Datta A., Bhattacharyya S.P. 1996. A new approach to feedback stabilization. Proceedings of 35th IEEE Conference on Decision and Control, 4: 4643-4648.

[9] Söylemez M.T., Munro N., Baki H. 2003. Fast calculation of stabilizing PID controllers. Automatica, 39 (1): 121-126.

[10] Shafiei Z., Shenton A.T. 1997. Frequency-domain design of pid controllers for stable and unstable systems with time delay. Automatica, 33 (12): 2223-2232.

[11] Tan N., Kaya I., Atherton D.P. 2003. Computation of stabilizing PI and PID controllers. Proceedings of 2003 IEEE Conference on Control Applications, 876-881.

[12] Avcı Ü. 2010. İki Yüzey Arasında Hacim Hesabı Yapan Program ve Algoritma Geliştirme. Yüksek Lisans Tezi, Selçuk Üniversitesi, Fen Bilimleri Enstitüsü, Konya.

[13] Delaunay B. 1934. Sur la sphère vide. A la mémoire de Georges Voronoï. Classe des sciences mathématiques et naturelles. Bull. l'Académie l'URSS, 6 (1): 793-800.

[14] Amidror I. 2002. Scattered data interpolation methods for electronic imaging systems: a survey. J. Electron. Imaging, 11 (2): 157.

[15] Franko S. 2010. İnsansız Helikopterin Model Öngörülü Kontrolü. Yüksek Lisans Tezi, İstanbul Teknik Üniversitesi, Fen Bilimleri Enstitüsü, İstanbul.

[16] Mettler B. 2003. Identification Modeling and Characteristics of Miniature Rotorcraft. Boston, MA: Springer US.

[17] Feedback Instruments, 2006. Twin Rotor MIMO System Control Experiments Manuel 33-949S. http://www.cpdee.ufmg.br/ palhares/33-942rotor.pdf (Erişim Tarihi: 24.12.2019). 